\title{
A REFLEXÃO COLABORATIVA COMO INSTRUMENTO PARA DESVELAR TEORIAS PESSOAIS E DESENVOLVER A PRÁTICA PEDAGÓGICA
}

\author{
NiLVÂNia Damas Silva Lima*
}

\begin{abstract}
RESUMO
Esta pesquisa tem como objetivo desvelar algumas de minhas teorias pessoais acerca do processo de ensino e aprendizagem de língua inglesa, empregando a reflexão colaborativa como instrumento para o desenvolvimento de minha prática pedagógica. Os resultados mostram que a reflexão sobre as próprias teorias e a prática pedagógica pode levar ao crescimento profissional e que esta reflexão, quando feita em colaboração com os pares, pode promover mudanças na maneira como alunos-professores percebem a si próprios como profissionais, bem como no processo de ensino e aprendizagem como um todo.

PaLAVRAS-CHAVE: reflexão colaborativa, teorias pessoais, mudanças, formação de professores.
\end{abstract}

The collaborative reflection as instrument to uncover personal theories and develop the pedagogical practice

Abstract

This research aimed to uncover some of my personal theories in relation to the process of teaching and learning English as a foreign language, by means of collaborative reflection as an instrument to develop my own pedagogical practice. The results show that reflecting about our own theories and pedagogical practice can lead to professional development and that reflection, if it is done collaboratively between peers, can promote changes in the way student teachers perceive themselves as professional and also in the process of teaching and learning as a whole.

KEY wORDS: collaborative reflection, personal theories, changes, teaching education.

\section{INTRODUÇÃO}

Nos últimos tempos, a atividade de refletir sobre a própria prática vem se tornando bastante comum nos meios escolares. Professores têm utilizado essa estratégia a fim de se aprimorarem profissionalmente. Alguns teóricos, como Schön (1983, apud Zeichner; Liston, 1996), Zeichner e Liston (1996), salientam que a reflexão feita por professores pode ajudar

\footnotetext{
Professora de Língua Inglesa do Centro de Ensino e Pesquisa Aplicada à Educação/ UFG. E-mail: damassilvalima@yahoo.com.br
} 
na criação de novas teorias acerca do ensino de línguas, uma vez que é o educador quem melhor conhece a realidade do ambiente de sala de aula.

Levando-se em conta a possibilidade de o professor ser um produtor de teorias para o ensino, tende-se, atualmente, a ver a formação desse profissional "como um processo de desenvolvimento e de estruturação da pessoa que se realiza com o duplo efeito de uma maturação interna e de possibilidades de aprendizagem, de experiências dos sujeitos" (García, 1999 , p. 19). Sob esse ponto de vista, então, o professor deixa de ser visto como técnico, e passa a ser encarado como um "construtivista que processa informação, toma decisões, gera conhecimento prático, possui crenças, rotinas etc., que influenciam a sua atividade profissional" (García, 1999, p. 47).

Segundo Pessoa e Sebba (2006, p. 43), "a fim de que os saberes da prática e os da teoria possam se informar e se desenvolver mutuamente", a reflexão por parte do professor deve ser coletiva, contínua e buscar apoio nas teorias acadêmicas. Sendo assim, como sou professora de língua inglesa e muito me preocupam tanto o processo de aprendizagem do aluno como a minha formação profissional, decidi investigar minhas próprias teorias pessoais e minha prática pedagógica.

A pesquisa que aqui se apresenta foi desenvolvida em conjunto com uma professora-orientadora e quatro alunos-professores - três outros colegas e eu. A reflexão colaborativa foi o instrumento usado para a análise das aulas de cada participante. Além disso, após cada sessão de visionamento dessas aulas, decidíamos os textos teóricos que seriam lidos para uma posterior discussão. Foram filmadas duas aulas de cada participante, e as sessões de discussão foram gravadas em áudio e, em seguida, transcritas. São essas transcriçōes que embasaram a análise dos dados.

Os principais objetivos deste estudo é verificar quais são as minhas teorias pessoais acerca do processo de ensino e aprendizagem da língua inglesa; examinar minha prática pedagógica; investigar se houve mudanças em minhas teorias pessoais e em minha prática após as sessões de reflexão e, por fim, analisar como as teorias acadêmicas refletem-se na minha prática pedagógica. Para tanto, as perguntas de pesquisa que direcionam o estudo são: a) Quais as minhas teorias pessoais acerca do processo de ensino e aprendizagem mobilizadas nas seçôes de reflexão?; b) Que características da minha pratica pedagógica salientam-se nas sessões reflexivas?; c) Houve mudanças em minhas 
teorias pessoais e em minha prática pedagógica após as sessões reflexivas?; d) Quais teorias acadêmicas refletem-se em minha prática pedagógica?

Apresento, inicialmente, as teorias que embasam este estudo. Em seguida, descrevo, na seção intitulada $A$ realização do estudo, a metodologia empregada. Depois disso, exponho a análise dos dados e a discussão acerca destes e, por fim, na seção Consideraçôes finais - que, apesar do título, não tem a intenção de ser o fim dos questionamentos - mostro algumas idéias suscitadas ao longo da realização deste trabalho. Passo, então, a uma breve discussão sobre formação de professores.

\section{FORMAÇÃO DE PROFESSORES}

Diversas pesquisas e publicações na área de formação de professores têm sido desenvolvidas no Brasil. Lingüistas aplicados brasileiros, como Almeida Filho (1999), Vieira-Abrahão (2004), Leffa (2001), Gimenez (2002), Bárbara e Ramos (2003), Moita Lopes (1995), Blatyta (1999) e Magalhães (2004), vêm se dedicando a esse trabalho. García (1999, p. 22) define formação de professores como "um encontro entre pessoas adultas, uma interação entre formador e formando, com uma intenção de mudança, desenvolvida num contexto organizado e institucional mais ou menos delimitado".

Conforme Edmunson (1990, apud García, 1999, p. 80) afirma, a formação de professores deve contribuir "para que os professores em formação se formem como pessoas, consigam compreender a sua responsabilidade no desenvolvimento da escola e adquiram uma atitude reflexiva acerca do seu ensino". Não podemos deixar de salientar aqui que, obviamente, uma reflexão colaborativa e cooperativa surte um melhor efeito tanto no processo de aprendizagem do aluno como no desenvolvimento do docente como profissional. As palavras de Honoré (1980, apud García, 1999, p. 22) corroboram esta afirmação: "a formação, como atividade humana inteligente, caracteriza-se como uma atividade relacional e de intercâmbio, com uma dimensão evolutiva e destinada a atingir metas conhecidas".

Os recentes cursos de formação de professores têm dado uma maior importância à figura do professor como construtor do próprio conhecimento e gerador de teorias sobre esse último e acerca da aprendizagem como um todo. Segundo García (1999, p. 47), dessa forma os professores deixam de ser vistos como meros "técnicos que executam instruções e propostas elaboradas por especialistas" e passam a ser encarados como sujeitos 
de sua formação por meio das informações que detêm, das decisões que tomam, do conhecimento prático que geram, das crenças que possuem.

Esse pensar sobre si mesmo e sua própria profissão, segundo Head e Taylor (1997, p. 1), está centrado na "consciência pessoal (personal awareness) das possibilidades de mudanças e do que influencia o processo de mudança”, o que nos leva, então, aos assuntos de nossa próxima discussão: teorias pessoais, prática pedagógica e mudanças.

\section{TEORIAS PESSOAIS, PRÁTICA PEDAGÓGICA E MUdANÇAS}

O aluno-professor, no momento em que chega aos cursos de formação, traz consigo toda uma experiência prévia do que vem a ser o funcionamento de uma sala de aula e qual seria o papel do professor nesse ambiente. Segundo Vieira-Abrahão (2004, p. 131), os alunos-professores, "ao entrarem em contato com o conhecimento teórico-prático nos cursos de formação, [...] fazem uma leitura particular, o que traz reflexos para a construção de sua prática pedagógica”. Sendo assim, faz-se necessário que os alunos-professores identifiquem e compreendam suas próprias teorias pessoais, a fim de que possam se tornar professores reflexivos capazes de construir conhecimento e gerar mudanças significativas no que concerne ao processo de ensino e aprendizagem de língua inglesa.

Para Vieira-Abrahão (2004, p. 132), teorias pessoais são todo o conhecimento prévio que os alunos-professores trazem consigo - "crenças, pressupostos e conhecimentos que têm sobre o que está envolvido no processo ensino-aprendizagem da língua estrangeira". É justamente o desvelamento dessas crenças que, segundo essa mesma autora, proporciona aos alunos-professores a possibilidade de "analisar tanto as teorias acadêmicas quanto as práticas a que estará exposto durante seu processo de formação" (Vieira-Abrahão, 2004, p. 133). Assim sendo, o aluno-professor é capaz de compreender melhor sua própria prática pedagógica, podendo, assim, adquirir conhecimentos que o ajudem a se desenvolver como profissional.

Essa atitude reflexiva, certamente, implica em mudanças tanto nas teorias pessoais quanto nas práticas pedagógicas. Conforme Blatyta (1999, p. 78) salienta, refletir leva a mudanças e vice-versa: "mudanças implicam reflexão constante e contínua, e esta implica uma visão crítica que se constrói a partir do desequilíbrio provocado pelo confronto com outras alternativas, pela análise das contradiçōes e pelo conflito provocado por visões diferentes". 
Segundo ainda Blatyta (1999, p. 65), "a reflexão através da troca e do confronto de opinióes deveria ser cultivada e constantemente experienciada, se possível já desde os cursos de graduação". Nesse sentido, comungando com as idéias da autora, este estudo apresentou-se como uma oportunidade para que alunos-professores pudessem começar, já na graduação, a refletir sobre as suas teorias, sua própria prática e sobre a prática de outros professores, objetivando a compreensão do sentido da formação de professores nos dias de hoje.

Pennington (1995) afirma que as mudanças do professor ocorrem tanto no aspecto comportamental quanto no cognitivo. No entanto, tais mudanças somente ocorrem quando o professor sente a "necessidade de mudança - ou, pelo menos, que demonstre o desejo de experimentação - e as alternativas disponíveis". Mas as transformaçōes precisam permanecer ou continuar ocorrendo. Para tanto, faz-se necessário que o professor encontre motivação para levar a cabo suas descobertas sobre si mesmo e a própria prática.

Guskey (2002) ressalta que as mudanças ocorridas na prática pedagógica de um professor levam a uma melhoria na aprendizagem. Entretanto, as alteraçôes não ocorrem de um dia pra outro, como num passe de mágica. Essas modificaçốes demandam tempo e disposição por parte dos professores. No entanto, apesar das dificuldades, conforme Pessoa e Sebba (2006, p. 4) afirmam, "é preciso que a ele seja dada a oportunidade de tornar explícitas suas teorias pessoais e tomar consciência de sua prática, pois, sozinho, é muito difícil que possa percorrer o caminho da mudança”. Sendo assim, esse estudo apresenta-se, tanto para mim quanto para os demais participantes da pesquisa, como essa oportunidade de reflexão.

Nesse momento, em que a reflexão é mencionada como meio para desvelar teorias pessoais e considerar a prática pedagógica originadas dessas teorias, creio ser necessário fazer algumas consideraçōes sobre o que é um professor reflexivo.

\section{O PROFESSOR REFLEXIVO}

$\mathrm{Na}$ visão tradicional de ensino de línguas estrangeiras, o professor é visto como um mero executor de técnicas desenvolvidas por outros. Atualmente, principalmente nos últimos anos, tem-se visto o docente como "capaz de fazer julgamentos complexos baseados em uma compreensão profunda dos alunos e da disciplina" (Pessoa, 2002, p. 32), tornando-se, 
portanto, um professor reflexivo. Sob o ponto de vista de Zeichner e Liston (1996, p. 6), um professor reflexivo é aquele que

examina, estrutura e tenta resolver os dilemas da prática em sala de aula; é consciente e questiona as suposiçóes e os valores que traz para o ensino; está atento aos contextos institucional e cultural em que ensina; participa do desenvolvimento do currículo e envolve-se em esforços de mudança da escola; e responsabiliza-se por seu próprio desenvolvimento profissional.

A prática de refletir torna-se, nas palavras de Cavalcanti (1999, p. 181), iluminadora, uma vez que "quando começamos a examinar nossas próprias práticas, podemos detectar contradições entre o que dizemos e o que fazemos". Na maioria das vezes, não pensamos sobre o que fazemos, nós apenas realizamos o que nos é dado para fazer. No entanto, o surgimento de contradições, questionamentos ou dúvidas, faz com que brotem em nós professores - inclusive nos professores que ainda estão em formação - desejos de mudança. Esse pensar transformador (Magalhães, 2001) configura o que Schön (1983, apud Zeichner e Liston, 1996) chamou de reflexão-sobre-a-ação (a reflexão ocorre antes e depois de uma ação) e reflexão-na-ação (a reflexão acontece durante a ação). Sendo assim, neste estudo, voltamo-nos para a prática de refletir, principalmente sobre a ação, tendo como base ações já realizadas. Na seção a seguir, detalho como essas reflexões ocorreram.

\section{A REALIZAÇÃo do ESTUdo}

Esta pesquisa realizou-se no primeiro semestre de 2005 e contou com a participação de quatro alunos-professores do $5^{\circ}$ ano de graduação, que atuavam como professores de inglês no centro de ensino de línguas da faculdade em que cursavam licenciatura em Português e Inglês, e de um professor-orientador.

Foram gravadas duas aulas de cada participante que, posteriormente, foram assistidas por todos. A discussão feita foi gravada em áudio para que, depois, fossem transcritas. Cada um dos membros da pesquisa encarregou-se de transcrever a sessão de discussão de suas próprias aulas. Ao professor-orientador coube a transcrição da sessão reflexiva na qual os textos teóricos lidos foram discutidos. Esses textos eram escolhidos ao final das sessôes de visionamento e, via de regra, tratavam dos assuntos mais de- 
batidos pelos participantes durante as sessões. Os assuntos mais discutidos foram dar e checar instruçôes (Harmer, 1998; Scrivener, 1994); tempo de fala do professor e do aluno (Gower, Phillips; Walters, 1995); a interação na sala de aula (Ur, 1996); os estágios apresentação, prática e produção propostos pela Abordagem Comunicativa e o Ensino por Tarefas (Willis, D.; Willis, J.; 1996; Richards e Rodgers, 1986).

Foram utilizadas para a análise, as transcrições das nove sessões reflexivas, sendo oito sobre as aulas e uma sobre os textos teóricos, perfazendo um total de 110 páginas. A fim de preservar a identidade dos participantes (excluindo-se a mim mesma), estes serão denominados AP1, AP2, AP3, e a professora-orientadora, $\mathrm{PO}$.

\section{ANÁLISE DOS DADOS E DISCUSSÃO}

Quatro categorias foram estabelecidas: 1) minhas teorias pessoais acerca do processo de ensino e aprendizagem; 2) características de minha prática pedagógica; 3) mudanças em minhas teorias pessoais e prática pedagógica e; 4) aplicação de teorias lidas à minha prática pedagógica.

\section{MINHAS TEORIAS PESSOAIS ACERCA DO PROCESSO DE ENSINO E APRENDIZAGEM}

No trecho: [1] "Às vezes eu ajudo demais os meus alunos. Às vezes eu subestimo, eu acho, os alunos", acredito estar clara a visão de que o professor é quem deve ter um papel ativo dentro de sala de aula e de que aos alunos cabe o papel de meros receptores do conhecimento. É possível, assim, perceber que minha experiência como aprendiz reflete-se em minha prática pedagógica, uma vez que, no sistema escolar no qual fui educada, os papéis desempenhados por professores e alunos eram exatamente esses: detentor e receptor passivo do conhecimento, respectivamente.

O uso de L1 para explicar um tópico gramatical ou dar instruções é outro aspecto ao qual me refiro. Acredito que o uso de L1 não é um fator positivo e que este deve ser o último recurso empregado para fazer com que os alunos compreendam a atividade: [2] "Eu optei, inconscientemente, por não usar o português e, talvez, eu tivesse que ter usado, porque com o nível iniciante a gente tem essa possibilidade de ter a mesma língua, essa facilidade. Eu só acho que temos de tomar cuidado para não usar o português o tempo todo; para que o português seja mesmo o último recurso. 
Que você tente de todas as formas: mímicas, cognatos, significados, sei lá, e o português ser o último". Além de acreditar que o uso de L1 em sala de aula não é muito positivo para os alunos, deixo transparecer que o emprego do português é aceitável apenas nos níveis iniciais, mas, mesmo assim, somente como último recurso.

Os demais participantes, por outro lado, parecem não concordar comigo quanto ao uso de L1 em sala de aula: [3] "Eu teria usado o português também, porque ali ela [eu] teria usado o português em outras estruturas. O português, nesse caso, funciona como um ponto de apoio" (AP1); [4] "O uso do português, nesse momento, não seria nenhum problema. Eu acho que, por ser um nível iniciante, você ia economizar muito tempo. É uma vantagem que nós temos e que a gente tem que aproveitar" (AP2).

A sugestão feita por AP1 de que não há problemas com o uso de L1 em estruturas diferentes daquelas focalizadas na aula em questão, desperta o seguinte comentário de PO: [5] "Mas eu não acho que ela tem que falar em inglês só as estruturas que estão sendo ensinadas. Pelo contrário, não sei se vocês viram, mas os alunos não aprendem somente o que os professores ensinam, eles aprendem muito mais. Aos poucos, eles [os alunos] vão poder entender uma palavra, outra, outra, mais palavras e vão ficar mais expostos à língua. Então, eu acho que isso é fundamental". A opinião do professor-orientador comunga com a minha. Ambos acreditamos que o constante uso de L1 durante as aulas pode prejudicar os alunos em seu aprendizado da língua inglesa. PO parece crer, assim como eu, que quanto mais expostos à língua os alunos forem, mais rápido e melhor será a aquisição da língua-alvo.

O professor como modelo para os alunos foi outra teoria que surgiu durante as sessões reflexivas. Os participantes parecem ser da opinião de que o professor, quando utiliza a L2, funciona como um modelo para os alunos seguirem. Minha própria fala mostra essa idéia: [6] "Concordo com você que a questão é bastante individual, mas eu ainda acho que, de certa forma, o professor te influencia”.

Outra de minhas teorias desvelada é que a aprendizagem de uma segunda língua é um longo processo e não é muito fácil para um iniciante, portanto, é necessário o uso de perguntas básicas: [7] "O caminho é mais longo. É verdade. Mais difícil. Mas para um primeiro nível é muito complicado. Então, tem que ser perguntas bem básicas". Percebe-se nessa fala que tenho a convicção de que o ensino de língua inglesa para os níveis 
iniciantes deve se dar a partir de perguntas mais simples, a fim de possibilitar o aprendizado por parte do aluno que tem pouco ou nenhum conhecimento da língua-alvo e que essa visão parece ser baseada tanto em teorias lidas anteriormente quanto em minha própria experiência em sala de aula. Por outro lado, ainda é possível encontrar resquícios de minha formação como aprendiz, que acredita haver uma ordem exata para que conteúdos sejam estudados, devendo, portanto, o ensino de língua iniciar-se pelas estruturas mais básicas.

Várias outras de minhas teorias pessoais foram desveladas durante a análise de dados, entretanto, no que diz respeito ao processo de ensino e aprendizagem de língua inglesa, acredito que aqui foram apresentadas as mais relevantes.

\section{CARACTERÍSTICAS DE MINHA PRÁTICA PEDAGÓGICA}

Nas diferentes sessões de reflexão foi possível identificar várias características de minha prática pedagógica. Uma delas é a forma empregada para dar e checar instruções. Muitas vezes, sinto-me insegura e, acreditando que os alunos não me entenderam, repito novamente as instruçôes e isso toma certo tempo da aula. AP1 percebe essa minha teoria ao dizer: [8] "Porque você guiou muito. Mesmo depois de explicar, você guiou muito a atividade. Então, talvez, se você tivesse checado as instruções dessa maneira: você explicava como faz e perguntava para os alunos qual era a ordem do que eles deveriam dizer".

Como foi possível perceber, dar e checar instruções é realmente uma grande dificuldade para mim. Em minha própria fala, nessa mesma sessão, deixo claro que esse é realmente um problema que enfrento ao lidar com o ambiente de sala de aula: [9] "Explicar, eu expliquei, mas o que falta aí de novo é o problema da instrução, da checagem da instrução, que eu continuo achando que ainda é o meu problema". Também é possível perceber que estou atenta a esta dificuldade e que venho tentando encontrar formas de melhorar essa minha prática.

Uma outra característica de minha prática pedagógica que pude identificar foi a mudança de estratégia de uma aula para outra. Quando eu percebia que determinada atividade não funcionava como o esperado em um grupo, eu tentava realizá-la de um modo diferente no outro: [10] "Eu acho que eu demorei um tempo grande porque esse foi o primeiro grupo. Normalmente 
as minhas aulas mudam de um grupo para o outro. É porque eu percebo que eu tomei muito tempo da minha aula, então eu mudo alguma coisa".

Uma prática que utilizo, mas na qual não pareço acreditar muito é o drilling (repetição de palavras ou frases de maneira bastante controlada pelo professor): [11] "Eu faço drill. Nessa aula foi menos. É uma atividade que eu faço. Mas como a gente está inserido no Communicative Approach, a gente condena. Porque os outros condenam você acaba condenando um pouco o drill. A gente faz um drill, mas um mais light, digamos assim, mais tranqüilo, sem muita insistência naquele tipo de atividade".

Como foi possível notar, a atividade de drilling não é uma prática constante em minha sala de aula, porque creio que este tipo de atividade não comunga com a Abordagem Comunicativa em que se pauta o método de ensino utilizado na escola em questão.

As características de minha prática pedagógica, anteriormente apresentadas, são aquelas que puderam ser detectadas na análise das transcrições das sessões reflexivas referentes às minhas duas aulas gravadas.

\section{MudanÇAS EM MiNHAS TEORIAS PESSOAIS E PRÁTICA PEDAGÓGICA}

Pessoa e Sebba (2006) afirmam que as mudanças nas teorias pessoais e na prática pedagógica de um professor não ocorrem instantaneamente, esse é um processo gradual. A quantidade de aulas gravadas - duas de cada professor - para esta pesquisa não pode jamais refletir todas as possíveis mudanças que possam ter ocorrido nas minhas teorias pessoais e prática pedagógica. Em alguns casos, é possível detectar essas mudanças. Posso afirmar que as modificaçōes ocorrem mais facilmente na prática pedagógica do que nas teorias pessoais. Esta última depende de um maior tempo de reflexão por parte do professor, como também de estudo de teorias acadêmicas mais profundo e duradouro. Sendo assim, as mudanças que aqui apresento estão todas relacionadas à minha prática pedagógica.

$\mathrm{Na}$ segunda sessão reflexiva, na qual se analisou minha segunda aula, é possível perceber que já houve algumas mudanças no que diz respeito a "dar e checar instruçôes": [12] "Uma coisa que eu pude notar também, não sei se vocês notaram, mas eu aprendi a simplificar a minha maneira de explicar, porque é uma dificuldade que eu tinha: ficar perdendo um tempão explicando em inglês. $\mathrm{E}$ agora não. Eu já consigo me adaptar ao nível deles. Eu consigo diminuir me adequar o nível de língua 
ao nível deles. Então, eu acho que por isso eu consegui explicar e falar o tempo todo em inglês".

Fica claro no trecho [12] que algumas mudanças começaram a surgir a partir da minha própria análise, da opinião dos outros colegas e do professor-orientador sobre minhas aulas. É preciso salientar, nesse momento, que as mudanças são ainda muito incipientes, mas, apesar disso, podem mostrar a importância da reflexão colaborativa.

$\mathrm{Na}$ sessão de visionamento da segunda aula, pude constatar que houve uma considerável redução do meu tempo de fala: [13] "Eu acho que nem falei muito nessa aula. Eu expliquei o conteúdo, o tópico gramatical e depois não falei muito mais. Acho que meu TTT está baixo nessa aula. Eu acho que falei menos. Agora não fiz nem um eco, não repeti nada do que eles ficaram falando. Eu acho que só falei, dessa vez, quase que o necessário mesmo".

A redução do meu tempo de fala fez com que os alunos participassem mais da aula, como constatou AP2: [14] "Os alunos falaram mais, participaram mais. Até mesmo porque é final de semestre. Se fosse no começo do semestre, ela [eu] falando daquele tanto sem precisar ficar fazendo gestos, mímicas para os alunos entenderem, eles entrariam em parafuso. Mas agora não. No final do semestre, eles já conseguem entender".

Outra mudança em minha prática pedagógica que pude notar foi com a relação à repetição de minha parte de quase tudo o que os alunos falam em sala: [15] "Com relação ao eco, eu faço isso uma vez, na hora cai a ficha e, no próximo, eu peço um aluno pra repetir, ao invés de eu repetir". Essa foi uma modificação nitidamente causada pela leitura de textos teóricos e pela reflexão, conforme é possível perceber em: [16] "Mas só depois de descobrir que o eco era um problema, porque eu jamais tinha pensado no tal do eco".

De modo geral, acredito terem sido essas as mudanças mais relevantes que pude verificar.

\section{A TEORIA NA PRÁTICA}

Em diversos momentos, as teorias acadêmicas estudadas - quer na graduação, durante a pesquisa ou por conta própria - refletem-se em minha prática pedagógica. Esse aspecto é bastante evidente na quinta sessão reflexiva, na qual discutimos os textos teóricos mencionados anteriormente na seção $A$ realização do estudo. No entanto, conforme veremos, nem 
sempre é possível aplicar as teorias acadêmicas a nossa prática pedagógica. Minha fala pode ser tida como prova disso: [17] "Eu tento ao máximo, mas... Eu conheço teorias, você tem sugestões de um e de outro, mas é difícil aplicar isso na hora lá".

Fica bastante evidente nesse trecho que o conhecimento de teorias nem sempre leva a mudanças, ou seja, os professores, principalmente os mais inexperientes, sabem que há algo errado, conseguem identificar tanto o problema quanto a possível solução apresentada por diversos teóricos, no entanto não conseguem fazer uso dessas teorias no momento em que tal problema ocorre.

No trecho a seguir, ao me referir a uma atividade usada para investigar o que os alunos tinham realmente aprendido na aula em questão e que devia seguir um roteiro preestabelecido por teóricos do ensino de línguas, mais uma vez é bastante evidente a dificuldade em aplicar as teorias conhecidas: [18] "Claro que essa não é uma boa estratégia. A gente tem outros meios de saber se o aluno realmente está gostando ou não da maneira como você trabalha". É possível notar que há, de minha parte, conhecimentos de procedimentos para a realização de atividades, no entanto eu não os utilizo. Não pude identificar a verdadeira razão disso ocorrer, mas creio que são decisões tomadas no calor da aula - Richards (1998) chama essa tomada de decisões de decision making.

Ao ler o texto de Harmer (1998), constato que muitas características apresentadas por ele do que vem a ser um bom professor reconheço em mim mesma. Pode-se dizer, então que a teoria é aplicada à prática, mesmo que inconscientemente: [19] "Eu li o texto e eu senti que muita coisa que ele diz aqui eu uso, que eu sou uma 'good teacher'. É claro que, a cada dia, a gente vai se aperfeiçoando mais, mas quando você está consciente de tudo o que ele diz sobre o que é ser um bom professor, eu acho que as aulas se tornam melhores e você se torna melhor profissional, porque você passa a refletir sobre as suas atitudes antes até de tomá-las".

Ao comentar o mesmo texto, AP3 ressalta que antes de lê-lo jamais havia pensado nos aspectos apontados por Harmer (1998): tornar a aula interessante para os alunos, fazer com que os alunos interessem-se pelas atividades criando uma atmosfera de suspense e outros: [20] "Antes de ler esse texto eu nunca tinha parado para pensar. A gente se viu nessas etapas".

Ao final de minha análise, o que pude verificar com relação à aplicação de teorias a minha prática pedagógica foi que ora eu o faço, ora não. 
Contudo, não é possível dizer, se quando utilizo alguma teoria, o faço conscientemente ou não. O que posso dizer, com certeza, é que, nas sessões de reflexão, após assistir as minhas aulas e as dos demais alunos-professores participantes, a associação com as teorias estudadas foi perfeitamente possível. Foi fácil identificar em quais situações minhas atitudes e as dos colegas embasavam-se em teorias e quais eram essas teorias. Mas a dificuldade em usar as teorias, quando se tem uma série de coisas para fazer e pensar ao mesmo tempo, permanece, como fica patente em: [21] "Mas aí, quando eu assisti minha aula, eu vi que não é bem assim. Uma coisa é concordar, achar que aquilo ali é útil e você defender aquela idéia. Outra coisa é você lá na frente, diante de todas as circunstâncias, os alunos, o tempo que está correndo, alguém que entra e atrapalha a aula, você lidar com tudo isso e continuar mantendo isso aqui [as estratégias mencionadas por Gower, Phillips e Walters, 1995]. Na teoria é tudo muito claro e ideal, aí lá na aula é que é a grande dificuldade".

Apesar de todas as dificuldades apresentadas acima, em nenhum momento, foi minha intenção dizer que as teorias não funcionam em sala de aula. Ao contrário, são essas teorias, por mais difícil que seja aplicá-las dentro da sala de aula, que têm me ajudado a ser uma professora de língua estrangeira um pouco melhor do que eu era antes de iniciar meu curso de graduação.

\section{CONSIDERAÇŌEs FinaIS}

Creio que esta pesquisa foi muito pertinente, uma vez que os objetivos traçados comungam com as afirmações de que a formação do professor deve iniciar-se na graduação. As reflexôes acerca das próprias teorias e práticas pedagógicas podem proporcionar crescimento profissional. E quando associadas à colaboração entre os pares podem promover mudanças bastante significativas no que diz respeito ao processo de ensino e aprendizagem.

Verificar quais eram as minhas próprias teorias pessoais acerca do processo de ensino e aprendizagem de língua inglesa, examinar a minha prática pedagógica, investigar se houve mudanças nas minhas teorias e na minha prática com as sessões de reflexão e, por fim, analisar como as teorias acadêmicas se refletiram na minha prática pedagógica foram os principais objetivos que nortearam esta pesquisa. 
104 Revista Solta a Voz, v. 18, n. 1

Nos dados que obtive, a primeira teoria pessoal identificada referese ao professor como o detentor do conhecimento e o aluno, o receptor. Logo em seguida, constatei que não concordo com o uso de L1 em sala de aula, pois penso que essa prática não é muito positiva para o processo de aprendizagem, devendo ser, portanto o último recurso a ser empregado pelo professor durante uma aula. De acordo com minhas teorias, ao usar mais a L2, o professor passa a ser um modelo para o aluno no que se refere ao uso da língua, logo a aprendizagem será expandida, pois o discente estará mais exposto a diferentes aspectos da língua-alvo. Outra de minhas teorias é a crença de que é necessário certo nível de conhecimento da língua para que o aprendiz possa realizar determinadas atividades. Por fim, conforme minhas teorias pessoais identificadas nesta pesquisa, a aprendizagem de uma língua estrangeira é um processo longo e não muito fácil para os iniciantes.

Com relação às características de minha prática identificadas aqui, posso dizer que muitas delas refletem a minha própria experiência como aprendiz, ou seja, a forma como realizo esta ou aquela aula está estreitamente relacionada, principalmente, com a maneira como fui ensinada. As peculiaridades apresentadas foram: insegurança ao dar e checar instruçôes; realização de atividades de maneira diferente ao verificar que algo não havia funcionado bem no primeiro grupo para o qual lecionava; largo uso de L2 e; por último, a realização da atividade a que chamamos drilling - repetição de frases e sentenças, na qual não acredito inteiramente, por ser esta muito ligada à teoria behaviorista, a qual embasa métodos mais tradicionais de ensino de línguas.

Um dos meus objetivos era identificar se houve mudanças em minhas teorias pessoais e na minha prática pedagógica, no entanto isso não foi possível com relação as minhas teorias pessoais. Acredito que essas modificaçōes não tenham ocorrido devido ao curto espaço de tempo deste estudo. Ao contrário das teorias, pude constatar as seguintes alterações em minha prática pedagógica: passei a dar e checar as instruçôes de modo mais claro e conciso, e passei a repetir menos o que os alunos falavam, o que, conseqüentemente, maximizou o tempo de fala dos educandos.

No que diz respeito à aplicação das teorias acadêmicas na minha prática, creio poder dizer que, ao final da análise dos dados, nem sempre foi possível aplicar os meus conhecimentos teóricos a minha prática, visto que há situações inesperadas dentro de uma sala de aula que não permitem recorrer às teorias conhecidas. 
As possíveis mudanças que possam ter surgido em minhas teorias pessoais ou prática pedagógica são ainda bastante incipientes e podem ou não continuar ocorrendo. Posso dizer que disposição para implementá-las não me falta. Espero continuar a ter oportunidades como esse estudo, que me ajudou a desvelar parte de minhas teorias pessoais e a compreender melhor a minha própria prática pedagógica. Além disso, espero que esta pesquisa possa ser um ponto de partida para alunos-professores em formação universitária iniciarem um processo de reflexão crítica sobre as suas teorias pessoais e a sua prática pedagógica, que está sendo construída.

\section{REFERÊNCIAS}

ALMEIDA FILHO, J. C. P. de (Org.). O professor de lingua estrangeira em formação. Campinas, SP: Fontes, 1999.

BÁRBARA, L.; RAMOS, R. C. G. (Orgs.). Reflexão e açôes no ensinoaprendizagem de línguas. São Paulo: Mercado de Letras, 2003.

BLATYTA, D. F. Mudança de habitus e teorias implícitas: relação dialógica no processo de educação continuada de professores. In: ALMEIDA FILHO, J. C. P. de (Org.). O professor de lingua estrangeira em formação. Campinas, SP: Fontes, 1999. p. 63-81.

CAVALCANTI, M. do C. Reflexóes sobre a prática como fonte de temas para projetos de pesquisa para a formação de professores de LE. In: ALMEIDA FILHO, J. C. P. de. (Org.). O professor de língua estrangeira em formação. Campinas, SP: Fontes, 1999. p. 179-184.

GARCÍA, C. M. Formação de professores: para uma mudança educativa. Porto: Porto, 1999.

GIMENEZ, T. (Org.). Trajetórias na formação de professores de línguas. Londrina: UEL, 2002.

GOWER, R., PHILLIPS, D., WALTERS, S. Teaching practice handbook. Oxford: Heinemann, 1995.

GUSKEY, T. R. Professional development and teacher change. Teachers and teaching: theory and practice, v. 8, n. 3-4, p. 381-391, 2002.

HARMER, J. How to teach English. England: Longman, 1998. 
106 Revista Solta a Voz, v. 18, n. 1

HEAD, K.; TAYLOR, P. Readings in teacher development. Macmillan: Hong Kong, 1997.

LEFFA, V. J. O professor de linguas estrangeiras: construindo a profissão. Pelotas, RS: Educat, 2001.

MAGALHÃES, A. S. Compartilhando e aprendendo: uma perspectiva "dialógica" do planejamento de aula de professores em formação. In: LEFFA, V. J. O professor de linguas estrangeiras: construindo a profissão. Pelotas, RS: Educat, 2001. p. 137-155.

MAGALHÃES, M. C. C. (Org.). A formação do professor como um profissional crítico. São Paulo: Mercado de Letras, 2004.

MOITA LOPES, L. P. Linguagem/Interação e formação do professor. Revista Brasileira de Estudos Pedagógicos, v. 3, n. 179-181, p. 355-366, 1995.

PENNINGTON, M. C. The teacher change cycle. Tesol Quarterly, v. 29, n. 4, p. 705-731, 1995.

PESSOA, R. R. A reflexão interativa como instrumento de desenvolvimento profissional: um estudo com professores de inglês da escola pública. 2002. 256 f. Tese (Doutorado) - Programa de Pós-Graduação em Letras e Estudos Lingüísticos, Universidade Federal de Minas Gerais, Belo Horizonte, 2002.

PESSOA, R. R.; SEBBA, M. A. Y. Mudança nas teorias pessoais e na prática pedagógica de uma professora de inglês. In: BARCELOS, A. M. F.; VIEIRA-ABRAHÃO, M. H. Crenças e ensino de linguas: foco no professor, no aluno e na formação. Campinas, SP: Pontes, 2006. p. 43-64.

RICHARDS, J. C. Beyond training: perspectives on language teacher education. Cambridge: CUP, 1998.

RICHARDS, J.; RODGERS, T. Approaches and methods in language teaching. Cambridge: CUP, 1986.

SCRIVENER, J. Learning teaching. Oxford: Heinemann, 1994.

VIEIRA-ABRAHÃO, M. H. Crenças, pressupostos e conhecimentos de alunos-professores de língua estrangeira e sua formação inicial. In: (Org.). Prática de ensino de língua estrangeira: experiências e reflexões. Campinas, SP: Pontes, 2004. 
WILLIS, D.; WILLIS, J. Challenge and change in language teaching. Oxford: Heinemann, 1996.

ZEICHNER, K. M.; LISTON, D. P. Reflective teaching: an introduction. New Jersey: Lawrence Erlbaum Associates, 1996.

UR, P. A course in language teaching. Cambridge: CUP, 1996.

Recebido em: 27 set. 2006

Aceito em: 16 fev. 2007 